\title{
Placental Choriocarcinoma
}

National Cancer Institute

\section{Source}

National Cancer Institute. Placental Choriocarcinoma. NCI Thesaurus. Code C8893.

Choriocarcinoma that develops in the placenta. It is the rarest form of gestational choriocarcinoma. Metastases to the mother and infant may occur. 